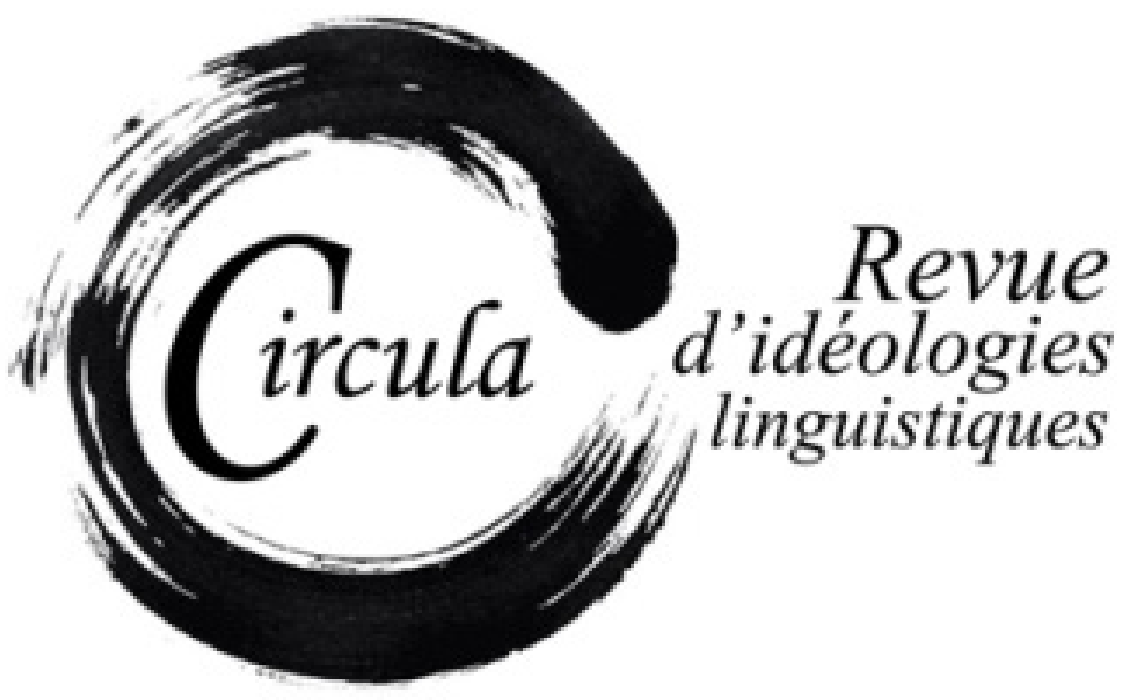

TITRE: JÓVENES DE TELEBACHILLERATO Y ALFABETISMOS DIGITALES. ENTRE EL ACCESO Y LA DESIGUALDAD

Auteur: María Guadalupe Velasco Giles, Instituto Superior de Ciencias de la Educación del

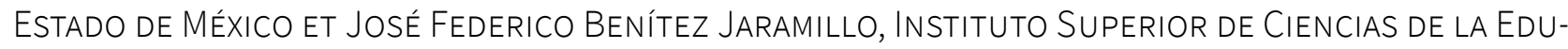
CACIÓN DEL ESTADO DE MÉXICO

Revue: Circula, NumÉro 12 : LA VULNÉRABILITÉ LINGUISTIQUE

DiRECTRICE: CLAUDIA TORRES CASTILLO

PAGES: $132-151$

ISSN: 2369-6761

URI: HTTP://HDL.HANDLE.NET/11143/18446

DOI: HTTPS://DOI.ORG/10.17118/11143/18446 


\title{
Jóvenes de Telebachillerato y alfabetismos digitales. Entre el acceso y la desigualdad
}

María Guadalupe Velasco Giles, Instituto Superior de Ciencias de la Educación del Estado de México maria.velasco@isceem.edu.mx

José Federico Benítez Jaramillo, Instituto Superior de Ciencias de la Educación del Estado de México jose.benitez@isceem.edu.mx

\begin{abstract}
Resumen: En el artículo, develamos prácticas de escritura realizadas por un grupo de jóvenes que asisten a un Telebachillerato Comunitario utilizando los dispositivos tecnológicos para comunicarse, relacionarse e interactuar a través de mensajes en los que alternan una variedad de lenguajes, símbolos, imágenes con textos. La perspectiva de alfabetismos digitales nos convoca a redefinir la cultura escrita, ya no solamente como la adquisición de la técnica del sistema de escritura, sino como actos que cuestionan las prácticas impuestas en la escuela. Las alfabetizaciones hoy implican prácticas y sentidos distintos a los que se evocan en la visión nostálgica de la escuela tradicional. La Investigación Tallerista fue una apuesta de trabajo horizontal, dialógico y colaborativo con agentes educativos. La narrativa oral y escrita, un recurso metodológico para escuchar las lecturas del mundo escolar. La categoría de interacción permitió articular aspectos como la comunicación, la relación intersubjetiva y los símbolos de carácter social.
\end{abstract}

Palabras clave: Telebachillerato; alfabetismos digitales; acceso y desigualdad

Abstract: In the article, we reveal writing practices carried out by a group of young people who attend a Community Telebachillerato using technological devices to communicate, relate and interact through messages in which a variety of languages, symbols, images and texts alternate. The perspective of digital literacy calls us to redefine written culture, no longer just as the acquisition of the technique of the writing system, but as acts that question the practices imposed in the school. Literacy today involves practices and meanings that are different from those evoked by the nostalgic vision of traditional schooling. The Workshop Research was a commitment to horizontal, dialogical and collaborative work with educational agents. Oral and written narrative, a methodological resource for listening to readings from the school world. The category of interaction made it possible to articulate aspects such as communication, inter-subjective relationships and social symbols.

Keywords: Telebachillerato; digital literacy; access and inequality 


\section{Introducción}

Los resultados aquí presentados se inscriben en la investigación colegiada del Cuerpo Académico Educación y poder. Acciones con grupos en condición de pobreza y contextos de vulnerabilidad que, desde una perspectiva sociocultural, problematiza las interacciones educativas en favor de escuelas participativas y equitativas. Epistémica y metodológicamente apuesta por la horizontalidad en la construcción del conocimiento, convocando al diálogo e interacción pedagógica a través de lo que denominamos investigación tallerista con jóvenes en diversas comunidades educativas.

Desarrollamos la investigación a través de la identificación de ejes de problematización que articulan Líneas de Generación y Aplicación de Conocimientos los cuales permitieron la construcción colectiva del problema de estudio. El primer Eje problemático se denominó Ejercicio del poder; el segundo Interacciones educativas y alfabetismos emergentes; (Eje que recuperamos para la construcción del presente artículo) y, el tercero, Comunidades educativas: participación, convivencia y nuevas territorialidades.

Compartimos la experiencia de investigación desarrollada en el 2018 con jóvenes de un Telebachillerato Comunitario del municipio de Tejupilco, situados en la Región Sur del Estado de México, a través de un taller nombrado: Narrativas de mi experiencia escolar. Emociones, relaciones y aprendizaje, cuyo taller potenció el encuentro dialógico con los y las jóvenes de un grupo de tercer grado de bachillerato, además de documentar sus voces, imágenes, escrituras; pero también sus problemáticas, gustos, tensiones y posibilidades de acceso a las tecnologías.

El objetivo que nos proponemos es develar otras expresiones lingüísticas utilizadas por jóvenes desde lo que hemos llamado alfabetismos digitales; además de conocer cuáles son las prácticas que tensan y ponen en conflicto su estar en la escuela, espacio que niega la posibilidad de coexistir junto con ellos. Es decir, los y las jóvenes cristalizan prácticas que refieren otros sentidos, otras formas de comunicación oral y escrita en el marco de sus necesidades, intereses y deseos que son soslayadas por la institución y por los tomadores de decisiones.

Entendemos los alfabetismos digitales no so lo como la lectura y la escritura con el uso de las tecnologías, sino además como "el dominio de los códigos, lenguajes y formas expresivas audiovisuales, hipertextuales, multimedia e interactiva” (Area, Gros y Marzal, 2014: 10). En la actualidad, los jóvenes suelen mezclar palabras con imágenes estáticas o en movimiento agregando música y sonido; no son solo consumidores pasivos sino también productores de sus propios textos, videos y ediciones, "para muchos jóvenes, escribir textos es sólo una forma de expresar ideas. Poco a poco están descubriendo que escribir con una mezcla de imágenes digitales, sonido y video es mucho más interesante y atractivo" (Knobel y Lankshear, 2013: 193). En nuestra visión se trata no sólo de mezclas de actividades, sino de alfabetismos en los que los diálogos tecnológicos con las letras virtuales, impresas, visuales se encuentran y desencuentran en la vida cotidiana de las personas. 
El escrito se estructura en cinco apartados: en primer término, se describe la situación problemática; un segundo momento presenta los planteamientos metodológicos y teóricos que dieron sustento a la investigación; el tercero alude a los alfabetismos digitales. Acceso y desigualdad; el siguiente describe el Telebachillerato Comunitario (en adelante TBC) como un espacio escolar en el Sistema Educativo Mexicano; enseguida recuperamos la experiencia de trabajo con los y las jóvenes estudiantes a través de sus alfabetismos digitales desde la investigación tallerista; para, finalmente cerrar con una serie de reflexiones que posibilitan seguir pensando en la emergencia de otros códigos de comunicación entre los jóvenes.

\section{Problematización}

El eje Interacciones educativas alfabetismos emergentes, implicó el reconocimiento de maneras distintas en el uso social del lenguaje, debido a que éstos se inscriben en un contexto de constantes transformaciones sociales y culturales, en el que el uso de las tecnologías como artefactos culturales da origen a otras formas de comunicación utilizando lenguajes que distan de los convencionales. El tema de la emergencia genera la posibilidad de reconocer estas prácticas situadas (Haraway, 1995), de tal suerte que proponemos el supuesto de que los alfabetismos digitales tienen un constitutivo central en la emergencia del sujeto educativo, social y colectivo en las formas en que se comunican a través de lenguajes virtuales. La emergencia hace también referencia no a un salir de la nada, sino a la visibilización situada, es una aportación no para dar la voz, sino para comprender en diálogo, desde una diversidad de lógicas que tensan, los procesos, prácticas, interacciones y narrativas que configuran a la juventud.

En este sentido, consideramos que surgen otros lenguajes a la hora de usar la palabra que permiten cuestionar no solamente las prácticas de comunicación que se pretende entablar, sino también las formas en cómo se comunican, con quiénes, para qué fines y con qué recursos (Giddens, 1998). De ahí que nos preguntamos ¿Cómo y con quiénes se comunican los jóvenes a través de alfabetismos digitales?, ¿Cuáles son los alfabetismos digitales presentes en su vida cotidiana?, ¿Con qué intención/es se comunican?, ¿Con qué sentidos?

Lo anterior, nos permite plantearnos que los cambios sociales y culturales que emergen desde la aparición de las tecnologías digitales, han derivado en transformaciones en las formas de comunicación, interacción y relación entre los sujetos; por lo que se requiere del análisis de estos fenómenos desde un enfoque sociocultural que recupere los diferentes niveles que los constituyen: social, cultural y comunicacional (García Canclini, 2004), es decir, recuperar las prácticas de comunicación situadas de las y los jóvenes. 
De ahí que, ante las transformaciones en el escenario sociocultural, político y económico no solo global sino también regional y local, algunos sujetos quedan excluidos debido a su condición geográfica, económica, de género y generacional, derivando en desigualdad, diferencia y desconexión (García Canclini, 2004). Así, hemos observado que varios de las y los jóvenes están desconectados no únicamente en términos del acceso a una red de comunicación sino además se quedan al margen de los beneficios que vulneran sus derechos. Hablamos del derecho en un sentido amplio, no únicamente como la posibilidad de acceso a los bienes y servicios más necesarios: la salud, la alimentación y la educación; sino, el derecho a un trabajo, a una identidad, a la participación, a un ambiente sano, a los medios digitales, ámbitos en los que lo educativo juega un papel significativo. Así, algunos sectores de la población si bien tienen acceso al sistema escolar, no tienen el poder adquisitivo para la compra de un dispositivo tecnológico, a sus programas y aplicaciones. Junto con el acceso a una computadora, resulta clave contar con acceso a internet, aunque este se ve limitado particularmente por su alto costo, sobre todo el internet de banda ancha (Sunkel, Trucco y Espejo, 2013).

En el período 2010 y 2015 se produjo un importante aumento en este indicador, con mayor fuerza en las áreas rurales, que mostraron un crecimiento del 414\%, frente a un 133\% en áreas urbanas. A pesar de este fuerte incremento en el área rural, su rezago con respecto de las áreas urbanas se mantuvo cercano a los 20 puntos porcentuales (Comisión Económica para América Latina y el Caribe, 2019: 48).

En el caso de la región latinoamericana, para los jóvenes, el acceso a las Tecnologías de la Información y de la Comunicación (TICS) es clave, tanto en los ámbitos de educación y empleo, como de conectividad en un mundo globalizado. No obstante, las diferencias socioeconómicas y geográficas dificultan su aprovechamiento.

Llama la atención la alta heterogeneidad entre países, el acceso a una computadora es inferior al $10 \%$ en áreas geográficas rurales y urbanas. Asimismo, el acceso a computadora en los hogares donde residen los jóvenes es mayor en áreas urbanas que en áreas rurales (Comisión Económica para América Latina y el Caribe, 2019: 47).

Exponemos la idea de que la juventud es contextualizada por el momento histórico en que "los jóvenes emergen como agentes sociales y, al hacerlo, plantean el necesario ejercicio de sus derechos sociales como miembros de un espacio" (Reguillo, 2000: 22), en este caso, los espacios educativos, sociales, culturales y comunitarios.

De acuerdo con datos del Centro Latinoamericano y Caribeño de Demografía aproximadamente 107 millones de personas en la región latinoamericana son jóvenes, lo que equivale al 17\% del total de la población. De estos, aproximadamente el 80\% vive en áreas urbanas (86 millones) y el $20 \%$ en áreas rurales (21 millones), diferencia que debería aumentar en los próximos años a favor de las áreas urbanas, debido en gran parte a los procesos migratorios de este grupo etario (Centro Latinoamericano y Caribeño de Demografía, 2017) 
El reconocimiento a la diversidad de prácticas de lectura y escritura de jóvenes dentro y fuera de la escuela permite sostener que la experiencia juega un papel crucial en sus procesos formativos como lectores y escritores y que está formada por un proceso complejo que involucra transformaciones dinámicas no sólo en cuanto al hacer, sino con relación en los conceptos de lectura, escritura y de sí mismos, a la intervención de los otros, a los usos que de ellos hacen y a la objetivación de estas perspectivas en la producción de textos escritos a través de los códigos escolares, a usos de tecnologías de la información y la comunicación, y las creaciones diversas que realizan con ellas.

En el contexto que habitan los y las jóvenes del TBC en el municipio de Tejupilco, ubicado en la Región Sur del Estado de México, se despliegan prácticas que visibilizan elementos de la cultura escrita; algunas de ellas no son nuevas y otras reformulan las posibilidades de encuentros en el marco de la escuela. Así, ante ciertas condiciones de desigualdad escolar, los jóvenes encuentran en los dispositivos digitales, principalmente, el teléfono celular, espacios para sus escrituras y lecturas que permiten la comunicación, la interacción y el acceso a la información que estos medios ofrecen a través de Internet.

En el taller desarrollado con los jóvenes señalaban haber aceptado ingresar el TBC debido a la gratuidad efectiva y la dinámica académica; evidencian que "aparece no sólo como una oferta que acerca la educación a aquellos lugares que no tienen otra opción, sino como la oferta que atiende a los que ya no pueden ser absorbidos por otros espacios" (Weiss, 2017: 13), aquellos que rebasan la edad establecida oficialmente para cursar la educación media superior, que han tenido trayectorias escolares "irregulares" y no cuentan con los créditos académicos para ser asignados en las escuelas céntricas, como expresaban los jóvenes. Cabe señalar que los jóvenes cuestionan las ideas de "tele" y "comunitario", con relación a lo primero advierten que no hacen uso de la televisión por ser propiedad de la telesecundaria -que tampoco hace uso de ella- que únicamente les prestan las instalaciones del edificio escolar para las clases y no los televisores o computadoras. Asimismo, cuestionan lo comunitario debido a que dicha categoría pierde sentido desde el momento en que no existe un proyecto que vincule realmente a la escuela con el espacio social.

En suma, si bien es cierto que muchas de las políticas sociales en México han soslayado los ámbitos rurales y urbano marginales; vemos que hoy día se está volteando la mirada hacia estos espacios, un caso particular es la aparición de los Telebachilleratos que surgen para comunidades consideradas dentro estos criterios. Estos espacios educativos juegan "en el imaginario juvenil un papel fundamental para considerarlo el factor más importante para conseguir un trabajo, más allá incluso de la experiencia laboral» (Instituto Mexicano de la Juventud, 2006: 16). En esta pertenencia o identidad por la escuela puede tener muchos significados y tienen que ver con los usos del lenguaje en el contexto social y cultural de una comunidad. 


\section{Planteamiento teórico y metodológico}

La metodología en la que nos apoyamos fue nombrada Investigación Tallerista, una apuesta de trabajo horizontal, plural, dialógico y colaborativo con agentes educativos (directivos, profesores y jóvenes estudiantes) que emerge de las inquietudes, problemáticas y necesidades de los propios sujetos que habitan la escuela, en la búsqueda de alternativas para la mejora educativa y la generación de conocimiento. La propuesta se adscribe a una perspectiva epistémica decolonial (De Sousa, 2010) que nos distancia de un trabajo extractivo de la investigación, para visibilizar o construir procesos político-pedagógicos de co-producción de conocimiento que potencien interacciones participativas y equitativas desde adentro y con las comunidades educativas, a partir del reconocimiento de sujetos epistémicos y de acción en la que colaborativamente con las y los jóvenes desarrollamos la investigación, haciendo hincapié de no construir conocimiento sobre los jóvenes, sino con los y las jóvenes.

La narrativa de y con los jóvenes estudiantes permitió una articulación compleja de la biografía/ acción/memoria susceptible de ser reflexionada a través de diversas mediaciones simbólico-narrativas (saberes, experiencias, lenguajes, normatividad, identidades, ideologías, valores, entre otros) en espacialidades y temporalidades diversas en las que se mueven los jóvenes.

El taller "Narrativas de mi experiencia escolar. Emociones, relaciones y aprendizajes" (2018) se desarrolló en las últimas dos horas de clase que reciben los jóvenes, donde en promedio asisten a clases que se desarrollan por las tardes un grupo de 20 jóvenes (13 mujeres y 7 varones cuyas edades oscilaban entre 17 y 21 años) con trayectorias sociales y escolares diversas; por ejemplo: algunos son padres o madres de familia, vivían en pareja o asistían con sus hijos a clases. Asimismo, varios llegaban al plantel expulsados de otras escuelas o se encontraban en condición de rezago educativo además de que la mayoría trabajaba por las mañanas.

Teóricamente ubicamos a la interacción como categoría que articula aspectos que tienen que ver con la comunicación, la relación intersubjetiva y los símbolos de carácter social. En este sentido, del Interaccionismo Simbólico retomamos las interacciones como construcción social y el lugar de la significación en la interpretación del mundo (Blumer y Mead, citados en Woods, 1998); De Bárcena y Mèlich (2014) se usa la idea de educación en su sentido ético y estético que supone que en la relación hay una presencia de otro frente al cual existe una responsabilidad. Finalmente, de Berlanga (2018) consideramos a la interacción como el encuentro intersubjetivo que se relaciona en encuentros y desencuentros con los otros desde la alteridad.

Así, el Interaccionismo Simbólico como lo plantea Blumer (1982), permitió considerar que, a partir de las interacciones, los jóvenes entablan la comunicación y la relación a través del lenguaje escrito alternando símbolos e imágenes en diversas superficies materiales y simbólicas. En razón de lo anterior, nos acercamos a la categoría de interacción más allá de una relación de dos personas, sino como una inter-acción, lo que supone relación con compromiso ético, habitada por nuestros proce- 
sos identitarios en co-presencia y en escenarios sociales que dan contenido al sentido común de la vida social, a su fragilidad, que implica al otro, que no está dada y que está siempre en posibilidad de configuración bidireccional, tanto de nuestros mundos simbólicos como de los contextos mismos.

La construcción de la mirada teórica hizo posible comprender las interacciones que los jóvenes del TBC entablan a través de los alfabetismos digitales para hacer lecturas de mundo a través de lenguajes y símbolos, en los que ponen de manifiesto sus preocupaciones e intereses. Así, nuestras interpretaciones van en el sentido de develar las diferentes interacciones que los jóvenes establecen con los lenguajes virtuales, con el entorno social que lo circunda y con los Otros con los que se comunica a través de mensajes orales y de texto, como son: comentarios, publicaciones, videos, memes, que se convierten en expresiones juveniles que expresan y comunican sus maneras de mirar y percibir sus mundos.

En torno a la comunicación suscribimos la tesis de que nos lleva a reconocer "nuevas expresiones políticas que inventan otros signos y desbordan las retículas de las grandes instituciones" (Reguillo, 2005: 11). No se trata pues de una perspectiva lingüística, en la que hay un emisor y un receptor en el acto de comunicarse e interactuar con el Otro; más bien, pretendemos recuperar una perspectiva sociocultural que reconoce la presencia del diálogo, la conversación y la interacción entre los sujetos que se comunican con ciertos propósitos e intenciones, lo que lleva a reconocer formas de comunicación dinámicas, cambiantes, pero que también retratan la desigualdad con relación al acceso a las tecnologías y a los múltiples lenguajes.

\section{Alfabetismos digitales. Acceso y desigualdad}

Consideramos relevante comprender las formas de vivir la juventud y el papel que juega la lengua escrita, por lo que la comprensión de sus códigos lingüísticos y de los motivos de la formación de una jerga particular puede dar un entendimiento de la naturaleza de la cultura juvenil, lo que a su vez "puede representar un factor, entre otros, en la programación de ayudas y en la superación de las barreras de comunicación”. (Zimmermann, 1996: 478), en este sentido, en la creación de variedades lingüísticas es necesario dar cuenta del lenguaje juvenil, ya que éste representa una de las variedades dentro de un sistema lingüístico en el que históricamente se construyen y re-producen cambios. Por tanto, damos cuenta de como el lenguaje juvenil se diferencia de este lenguaje estándar; en el uso de lenguajes digitales, ya que "los jóvenes luchan contra los tres aspectos: la norma escolar, el estilo culto y la cultura de los adultos" (Zimmermann, 1996: 483), es decir, sus prácticas digitales desbordan el alcance del pensamiento escolary adultocéntrico. Por ende, los "jóvenes" representan, sin duda, el grupo que ha creado la forma idiomática que más llama la atención. Para sí mismos "un símbolo de identidad sociolingüística" (Zimmermann, 1996: 484). 
Aludimos al acceso, como la posibilidad que tienen los jóvenes "para participar en eventos de lengua escrita en las cuales el sujeto se posiciona vis-a-vis con otros lectores y escritores y, a las oportunidades y modalidades que tienen para escribir" (Kalman, 2004: 8), en el caso expuesto, al hacer uso de los dispositivos tecnológicos como medios para plasmar sus lecturas y escrituras de mundo. De ahí que, no solo basta con tener un dispositivo sino además contar con el servicio de Internet que posibilite el acceso a las diferentes opciones que éste ofrece: sitios web, plataformas, aplicaciones, entre otras. Espacios virtuales que ofrecen diferentes opciones para comunicarse e informarse. Además de ofrecer una vasta variedad de textos que los jóvenes pueden leer.

Los jóvenes se mueven en infinidad de símbolos en los que construyen sus mundos y le dan sentido (Mélich, 1998), es decir, habitan espacios en los que vehiculizan y dan uso a los conocimientos que adquieren en la escuela, pero también hacen uso de otros códigos lingüísticos y símbolos, que emergen en el contexto sociocultural en el que se encuentran inmersos; ya que la cultura juvenil crea un espacio comunicativo (Zimmermann, 1996).

En este sentido, la escritura de los jóvenes no es "necesariamente lineal ni deductiva, tal como lo implica la inscripción de un texto sobre una página, sino que puede ser abierta, expandida y relacional gracias a la multiplicación de los vínculos hipertextuales" (Chartier, 2010: 36), en el que el texto electrónico reintroduce en la escritura un lenguaje simbólico y una lectura multimodal. De ahí que,

En el mundo contemporáneo en relación con la textualidad electrónica se esboza un nuevo idioma formal, inmediatamente descifrable por cada uno. Es el caso de la invención de los símbolos, los "emoticons", como se dice en inglés, que utilizan de una manera pictográfica algunos caracteres del teclado (paréntesis, comas, punto y comas, dos puntos) para indicar el significado de las palabras: alegría :-) tristeza :-( ironía ;-) ira :-) @ [...] llustran la búsqueda de un lenguaje no verbal que, por esta misma razón, pueda permitir la comunicación universal del registro del discurso (Chartier, 2010: 200-201).

Así, los y las jóvenes construyen sus propias simbologías para comunicarse haciendo uso de su imaginación, articulan diversos modos de comunicación en una red interactiva, en hipertextos que integran como parte de su historicidad en las modalidades escrita, oral y audiovisual (texto, imágenes y sonido), interactuando desde múltiples puntos, en un tiempo elegido (real o demorado) a lo largo de una red global, con acceso abierto y asequible, cambiando radicalmente el carácter de la comunicación humana (Castells, 2009). Por tanto, las tecnologías digitales de la información y la comunicación conforman entornos semióticos novedosos que son necesarios mirar desde los espacios escolares y sociales.

No se trata sólo de analizar a los sujetos en un espacio geográfico concreto, sino también analizar las relaciones lingüísticas que establecen con estos espacios, con las diversas formas de posicionarse de ellos y con el sentido de pertenencia y diferenciación que en muchas de las ocasiones los excluyen, ya que: 
La relativa unificación globalizada de los mercados no se siente perturbada por la existencia de diferentes y desiguales: una prueba es el debilitamiento de estos términos y su reemplazo por lo de inclusión o exclusión [...] los incluidos son quienes están conectados y sus otros son los excluidos [...] ahora el mundo se presenta dividido entre quienes tienen [...], acceso a la información y el dinero, y, por otro lado, los que carecen de tales conexiones (García Canclini, 2004: 73-74).

La construcción de la mirada de alfabetismos emergentes implica el reconocimiento de maneras distintas en el uso social del lenguaje, reconociendo las otras formas de comunicación y no excluirlas; debido a que emergen otras performatividades que se hacen en ciertas superficies materiales y simbólicas de escritura; que cuestionan no exclusivamente las formas de comunicación que se pretende entablar, sino con quiénes, para qué fines y con qué recursos; éstas dan cuenta de la agencialidad de los jóvenes para expresar su decir a través de la palabra escrita, ya no sólo impresa en la superficie de un papel o una pizarra sino a través de lenguajes que representan "nuevas formas de pensar el mundo y responderle" (Lankshear y Knobel, 2010: 43), dando origen a otras textualidades no reconocidas por la sociedad y las instituciones escolares, quienes parecen mantenerse estáticas frente a las transformaciones sociales y culturales que acontecen al exterior.

Derivado de lo anterior, surge una divergencia generacional y una incompatibilidad entre lo que la escuela ofrece a los jóvenes en torno a las prácticas de lectura y escritura y lo que ellos demandan y necesitan de acuerdo con intereses, inquietudes y necesidades. Por ello se afirma al respecto que:

La escuela está en crisis [...], esa institución, pensada como una tecnología —es decir, como un dispositivo, como una herramienta o un complejo artefacto destinado a producir algo-, es incompatible con los cuerpos y las subjetividades de los chicos de hoy en día (Sibilia, 2012: 135).

En tal sentido, el cuerpo y la subjetividad de los jóvenes se encuentran en diputa con la escuela, quien insiste en vestir y controlar los cuerpos, en uniformar los pensamientos, las acciones y el hacer de los jóvenes.

Al preguntar qué significa hoy ser joven, encontramos que la sociedad que se responde que su futuro es dudoso o que no sabe cómo construirlo está contestando a los jóvenes no sólo que hay poco lugar para ellos. Se está respondiendo a sí misma que tiene baja capacidad, por decir así, de rejuvenecerse, de escuchar a los que podrían cambiarla (García Canclini, 2004: 168).

Hoy día los usos diversos que innovan los jóvenes de lo virtual y por primera vez en la historia de la humanidad, vemos una nueva generación que está capacitada para utilizar la tecnología mejor que sus padres. En términos de Mead (2006), estamos frente a una cultura "prefigurativa", en la que son los jóvenes quienes enseñan a sus padres los usos que se les dan a diversos artefactos tecnológicos, 
como es el caso del celular, la computadora, entre otros, sin embargo, se considera que se está ocasionando una ruptura con la escuela, espacio donde no existe la apertura a otras expresiones que los jóvenes hacen visibles a través de las diversas prácticas sociales de alfabetismos emergentes. Por consiguiente, es importante comprender el mundo simbólico del tiempo y espacio de los jóvenes y su vínculo pedagógico con las redes electrónicas digitales y con las formas de escribir y de leer la realidad.

Por tanto, reconocemos que la presencia y el uso de las tecnologías digitales ha dado origen a otras formas de relación, comunicación e interacción entre las nuevas generaciones, y entre éstas con la letra escrita, quienes se encuentran ante una diversidad de lenguajes virtuales: textos, imágenes y sonidos frente a la superficie plana de una pantalla luminosa que, de alguna forma, rompen o adelgazan el antiguo lazo anudado entre los textos y los objetos, entre los discursos y su materialidad. "La revolución digital de nuestro presente modifica todo a la vez, los soportes de la escritura, la técnica de su reproducción y diseminación, y las maneras de leer" (Chartier, 2010: 34), ante ello, cabría preguntarnos cómo se está leyendo, qué y para qué se lee, qué posibilidades ofrece el TBC para potenciar los alfabetismos emergentes y cómo se da acceso o no a estos nuevos alfabetismos.

\section{El Telebachillerato Comunitario en el Sistema Educativo Mexica- no}

Ante lo aludido en párrafos anteriores, es importante aclarar cómo, por qué y para qué surgen los TBC, así encontramos que ante la consigna de ampliar la cobertura en el nivel medio superior responde a las modificaciones realizadas en el marco legal, particularmente en la Constitución Política de los Estados Unidos Mexicanos en la que se estableció la obligatoriedad de la Educación Media Superior en el 2012, servicio educativo destinado a la población de entre 15 y 17 años. Con la promesa de la igualdad de acceso, equidad, calidad e inclusión, surgen además una serie de documentos oficiales en los que se plantea una educación con tales características.

En tal sentido, pensar la educación como un derecho que los sujetos jóvenes situados en contextos rurales y urbanos marginados vulneran su condición, porque además de la carencia material enfrentan también la desigualdad académica; desde el perfil profesional de quienes atienden estos espacios educativos -en su mayoría con una formación técnica-; los tiempos, horarios y contenidos; las oportunidades de acceso al nivel superior, el asumir el estigma social que los discrimina "por ser los alumnos que otras escuelas no quieren", entre otras condiciones que los colocan ante una situación de desigualdad con respecto a aquellos jóvenes que asisten a un bachillerato general.

Las desigualdades de los estudiantes no se distribuyen aleatoriamente en el sistema educativo una vez que han sido "incluidos" diversos aspectos confluyen para que, a través de un proceso de autoasignación, los alumnos con mayores desventajas atiendan a un tipo de escuela y los alumnos con mayores ventajas otro (Saraví, 2015: 67). 
El origen de los Telebachillerato Comunitarios (TBC) en México se atribuye a la carencia de instituciones de educación media superior en localidades pequeñas donde no resulta factible establecer un plantel en cada una de ellas. Inicialmente este servicio educativo estuvo pensado para comunidades con características de ruralidad; sin embargo, hoy día se pueden encontrar también en zonas urbano marginales de algunas ciudades. Estas escuelas deben establecerse en comunidades con una población menor a 2500 habitantes, que no cuenten con oferta de Educación Media Superior (EMS) en por lo menos $5 \mathrm{~km}$ a la redonda y que posean instalaciones que puedan facilitar para su funcionamiento, por ello se consideraron a las telesecundarias como opciones ideales (Secretaria de Educación Pública, 2014).

Esta propuesta educativa surge en agosto de 2013, en una etapa de pilotaje con 253 centros; en 2014 se incrementó a 1497; en agosto de 2015 se abrieron 1168 teniendo un total de 2918 centros que atienden una matrícula de 104 mil estudiantes y donde participan 8859 docentes. Las cifras más recientes de noviembre de 2018 refieren la existencia de 3309 planteles en el país que atienden 139,193 estudiantes. Este subsistema es el que representa una mayor expansión en los últimos años debido a los bajos costos que implica su instauración, pues las clases se desarrollan, en su mayoría, en las instalaciones de escuelas telesecundarias cuya infraestructura y mobiliario es utilizado por los profesores y estudiantes de esta modalidad; los turnos son vespertinos por lo que, muchos de los profesores que los atienden trabajan por la mañana en otros niveles educativos.

La planta docente es reducida (únicamente tres docentes) y alguno de ellos también cumple las funciones de Director. Cada maestro se encarga de impartir una serie de materias divididas en tres áreas disciplinares: Matemáticas y Ciencias Experimentales; Ciencias Sociales y Humanidades; y Comunicación. La modalidad educativa es presencial, los alumnos realizarán 80\% de actividades de aprendizaje bajo la mediación del profesor y el 20\% bajo el esquema de estudio independiente.

Estas condiciones de desigualdad y exclusión se hacen presentes en los jóvenes que asisten al Telebachillerato de "El Molino", en una colonia urbano marginal del municipio de Tejupilco, en el Estado de México. Esta colonia se ha caracterizado por ser habitada por familias que han emigrado de los estados de Michoacán, Guerrero y Morelos, principalmente, lo que la convierte en un mosaico sociocultural. Sin embargo, las situaciones por las que llegan a este espacio es porque están huyendo de los grupos delincuenciales o para mejorar sus condiciones económicas y sociales, lo que acentúa la desigualdad y la exclusión; como lo puntualiza Saraví (2015), no tienen la oportunidad de elegir otra escuela, sino que la escuela los elige a ellos por su condición de ser joven vulnerado y vulnerable. Empero, esta diversidad cultural que se hace visible en las aulas y en el espacio escolar, enriquece la comunicación y el lenguaje mediante sus expresiones emergentes. De ahí que consideremos que el lenguaje "es un medio por el cual el hombre puede comunicarse con el otro, es un juego de codificación y decodificación de signos y símbolos que posibilitan la comprensión y transmisión de información” (Espejel, 2014: 79). 


\section{Los jóvenes del Telebachillerato y sus alfabetismos digitales}

Como hemos venido señalando, las formas de comunicación que comparten los jóvenes son diversas, ya que ellos, pese a su procedencia geográfica y social, convierten el espacio escolar en un encuentro dialógico diversificado culturalmente; lo que les coloca ante la necesidad de apropiarse de los códigos lingüísticos que no le son propios y que los coloca ante una condición de desigualdad lingüística. En este sentido, la palabra escrita juega un papel importante en la comunicación, pero también en el logro de los vínculos sociales, afectivos y pedagógicos.

Algunos ejemplos de ello son las siguientes expresiones TQM que es la abreviatura de las palabras "te quiero mucho"; NTP para expresar "no te preocupes"; ADV (Asco De Vida), pero también tiene su versión en inglés FML (Fuck My Life) y sirve para expresar que algo no ha salido como esperaban, sino bastante peor. Otras abreviaturas derivadas del idioma inglés son: ILY para abreviar las palabras "I love you"; BFF Best Friends Forever "mejores amigos para siempre"; además de algunas letras y números como los siguientes: "X2" que para los jóvenes significa compartir el punto de vista de otra persona que expresa una opinión en redes sociales; "+1" es una de las abreviaturas más famosas y se utiliza para expresar que algo que les gusta mucho y si quieren mostrar más énfasis en ello, pueden añadirle ceros "+10" a los cuales suelen agregar emoticones para expresar emociones o estados de ánimo, como por ejemplo: carita feliz, llanto, enojo, asombro, entre otras.

Esta serie de palabras, signos y emoticones son significativas en la comunicación de los jóvenes; sin embargo, muchos de los códigos no son siempre comprendidos por algunos de los jóvenes, quedando siempre resquicios en la comunicación. Los jóvenes usan estas expresiones porque les permite sentirse diferenciados, pertenecer a un grupo y fortalecer la empatía entre iguales; pese a que no son aceptadas por la mirada adultocéntrica, ellos potencian el establecimiento de códigos que lo diferencien de otras generaciones creando su propio mundo. De ahí que sea importante conocer el significado de estas expresiones para poder entender las relaciones en las que convergen.

Durante una de las sesiones del taller que se desarrolló con los jóvenes estudiantes del Telebachillerato Comunitario, se propuso trabajar el Eje: "Escrituras en red", las preguntas que posibilitaron el diálogo fueron: ¿Con quiénes me comunico e interactúo en las redes sociales?, ¿Qué escribo en la Internet?, ¿Qué leo en Internet?, ¿A qué páginas acceso con mayor frecuencia?, ¿Utilizo la Internet para investigar algún tema o tarea escolar?

De los 20 jóvenes participantes, solo 18 enviaron sus respuestas al número de WhatsApp que previamente les compartimos. En el diálogo que surgió a partir de sus respuestas, los jóvenes comentaron que la red social de mayor uso es Facebook 50\% (9 estudiantes), seguida de WhatsApp 22.2\% (4), Instagram 16.6\% (3), y Twitter 11.1\% (2), espacios virtuales en los que realizan escrituras y lecturas digitales. Cabe señalar que algunas de estas plataformas digitales son de carácter público, es decir cualquier persona puede tener acceso a sus datos, por lo que algunos jóvenes usan nombres anónimos o algún seudónimo. Mientras que en WhatsApp utilizan su número personal del celular, lo 
que le otorga un carácter más privado. Los jóvenes establecen diferencias entre una red social y una aplicación; señalan Facebook, Instagram y Twitter como redes sociales; mientras que a WhatsApp la ubican como una aplicación. Además, utilizan más de una red social, así que los datos ofrecidos responden a cuál de ellas pusieron como primera, segunda y/o tercera opción.

Entre las personas con las cuales se comunican colocan en primer término a sus amigos y/o amigas 94.4\% (17 jóvenes) y 5.5\% a la familia (1 joven). De igual manera, ponían una primera, segunda o tercera opción; por ejemplo, 2 de los jóvenes colocaron a sus parejas sentimentales como segunda opción, después de sus amigos. Así también, solo una joven comentó que usa WhatsApp para comunicarse con sus maestros.

Con respecto a las publicaciones que realizan, 9 (50\%) dijeron que "memes"; 8 (44.4\%) fotografías personales y solo un joven publica noticias (5.5\%). En su mayoría, los jóvenes utilizan las redes como diversión o recreación, para enterarse de lo que otros publican. Es en estos espacios virtuales donde las y los jóvenes realizan lecturas y escrituras digitales, 5 (27.7\%) expresan leer lo que otros publican; 4 leen noticias (22.2\%) aunque no especifican de qué tipo; 2 (11.1\%) leen memes y 7 (38.8\%) no escriben ni leen en redes. Entre sus segundas opciones, una joven comentó que escribe sus estados de ánimo o frases motivacionales que puedan ayudar a quienes las leen; otra dijo interesarse por leer recetas de cocina.

Los 18 jóvenes (100\%) que enviaron sus respuestas a través de WhatsApp aceptaron hacer consultas en la Internet para sus tareas escolares. Las plataformas y páginas de mayor acceso son Google Académico 13 (72.2\%); Wikipedia 2 (22.2\%); Redalyc 2 (11.1 \%) y Webassing 1 (5.5 \%); 11 (61.1\%) jóvenes han leído algún libro en Internet y 7 (38.8\%) no han realizado lectura de libros electrónicos. En cuanto a sus preferencias literarias 5 (27.7) muestran agrado por los textos de ficción; otros 4 (22.2\%) por las novelas y 2 (11.1\%) por textos científicos.

Los datos anteriores develan que los jóvenes realizan sus lecturas y escrituras digitales de acuerdo con sus intereses, necesidades, emociones y motivaciones. Los propósitos son diversos y van desde la diversión y esparcimiento hasta enterarse de noticias, comentar las publicaciones de otras personas o manifestar su opinión sobre los temas que ahí se exponen.

Otra de las actividades de escritura que se les propuso a los jóvenes participantes en el taller fue elaborar un "meme" haciendo uso de sus celulares; bajo las preguntas: ¿Qué me gusta de la escuela?, ¿Qué me disgusta? Si pudiera, ¿Qué cambiaría de la escuela?

Previo a que dieran inicio con la actividad, les preguntamos si sabían que era un meme. Después de escuchar algunas opiniones les compartimos la siguiente información: 
El meme más allá de imágenes cómicas y del señalamiento de algunas figuras reconocidas (como artistas, políticos, deportistas, etc.) se trata de enunciaciones que responden a una amplia variedad de satisfactores [...] puede tener muy diversas formas de expresión cultural. Puede ser desde una frase (los refranes populares serían un buen ejemplo), una imagen (la Mona Lisa reproducida en litografías, camisetas, entre otros), o bien, presentarse a partir de diversas formas simbólicas disponibles en internet, como videos virales o imágenes que son reproducidas a través de las redes sociales (Pérez Salazar, 2014: 113-115).

Cabe señalar que, en términos pedagógicos, la elaboración de un meme implica el desarrollo de habilidades como la imaginación, la creatividad, el uso y manejo de diversos recursos materiales y tecnológicos de los cuales los jóvenes echan mano para realizar sus creaciones. Así mismo, requiere el manejo de las tecnologías como artefactos culturales que demandan otras formas de leer y escribir el mundo. De esta manera el joven no es únicamente consumidor pasivo de las escrituras de otros sino también es productor de sentidos y significados a través de lo que escribe y expresa por medio del celular. De ahí que, las escrituras digitales muestran a los jóvenes de la escuela como sujetos que aprenden el manejo técnico de un aparato, pero también aprenden otras maneras para comunicarse, interactuar e informarse mediante la letra escrita. Para desarrollar la actividad se formaron equipos de cuatro integrantes, quienes tomaron acuerdos con respecto al tema del que hablarían en el meme. Se puntualizó el tiempo que dispondrían para desarrollar la actividad. Algunos jóvenes salieron del espacio (el laboratorio) que se nos había facilitado para desarrollar las sesiones del taller y hacer un recorrido, tomar fotos o simplemente para trabajar afuera. A su regreso compartimos nuestro número de WhatsApp para que nos enviaran sus elaboraciones, algunos intercalaron imágenes, fotografías y textos; otros, imágenes bajadas de la red con textos escritos por ellos mismos. Los memes se proyectaron utilizando un cañón para que pudieran ser observados por todo el grupo y los integrantes de los equipos explicaran su contenido. Enseguida mostramos las elaboraciones escritas de algunos equipos.

El primer equipo muestra un "meme" con la imagen de "Patricio" arrastrando a "Bob Esponja" (personajes de una caricatura infantil); la imagen es descargada de Internet, tiene como encabezado la frase "When te hacen bullying y la orientadora solo Te engaña diciendo QYa No Pasará"; en la parte inferior de la imagen hay otra frase que dice: "No te preocupes, estarás bien"; los jóvenes agregaron el texto: "Cuando Le Decimos A Los maestros algo \& no hacen nada".

Otro equipo refiere una fotografía de la cancha de futbol rápido, en la cual los jóvenes manifiestan su inconformidad por el descuido en que se encuentra por la falta de mantenimiento en esta área de esparcimiento y deporte. La foto va acompañada de un texto escrito por ellos mismos "Una De Las Principales Areas Q necesitan Un Mejoramiento Para Todo El Alumnado \& Docentes Para Poder Realizar Distintas Actividades Físicas O Juegos Deportivos". (La transcripción de los empíricos aparece tal cual fueron escritas por los jóvenes). 
Cabe destacar en estos empíricos el uso que hacen los jóvenes de algunos términos en inglés como "when" y "bullying", el símbolo "\&" (traducido como "and" en inglés y en español "y") de uso común entre ellos; además de usar una sola letra "Q" para enunciar la palabra "que" de manera abreviada. De ahí que, para entender el contexto en el que se mueven los jóvenes resulta fundamental entender la estructuración de los diferentes espacios y lenguajes en los que se mueven.

En este sentido, la creación de nuevas variedades lingüísticas es necesario dar cuenta del lenguaje juvenil, ya que éste representa una de las variedades dentro de un sistema lingüístico en el que históricamente se construyen y re-producen cambios lingüísticos. Por tanto, damos cuenta de cómo el lenguaje juvenil se diferencia de este lenguaje estándar. Para esto "Ios jóvenes luchan contra los tres aspectos: la norma escolar, el estilo culto y la cultura de los adultos". (Zimmermann, 1996: 483).

En suma, abordar las expresiones lingüísticas de los jóvenes a través de alfabetismos digitales aporta experiencias teórico empíricas que ayudan a mirar cómo las personas se convierten en usuarios de nuevos códigos para comunicarse, relacionarse e informarse. Esta posición tiene relación estrecha con el desarrollo teórico de los estudios socioculturales sobre las prácticas sociales de la lengua escrita (Kalman, 2004) y su apropiación por parte de los jóvenes. Los estudios que se muestran en la investigación sociocultural sugieren una especie de imbricación entre la práctica y los contextos en que éstos tienen lugar. Esto es, que las acciones desarrolladas por los jóvenes en la consecución de ciertas metas se configuran en interacción con las circunstancias que los rodean. Así, el acceso a las prácticas sociales, es un proceso contextualizado; un proceso imbricado en el desarrollo mismo de las prácticas, donde la interacción entre los aprendices constituye una mediación social.

\section{Reflexiones finales}

Hablar de alfabetismos digitales de los jóvenes nos convoca a reflexionar; en primer término, con otros lenguajes que se alejan de los convencionalismos pedagógicos y sociales establecidos históricamente; así desde el pensamiento adultocéntrico es importante abrirnos para poder remirar el mundo de escrituras y lecturas de las culturas juveniles que aportan conocimientos a los debates actuales en América Latina. De ahí que los aportes de los y las jóvenes tendrían que ser constitutivos tanto de los cambios culturales y tecnológicos como de las nuevas formas de comunicación social que se instituye como parte de la propia existencia.

Narrar las experiencias educativas de las y los jóvenes viabilizó el comprender los acontecimientos situados espacial y temporalmente en el uso de sus cuerpos donde también escriben y narran con imágenes, símbolos, códigos que se tatúan en el marco de sus historias que cristalizan en amores, desamores y utopías. Son lecturas y escrituras de poder e intersubjetividades que nos conmueven a ser escuchados. 
Asimismo, las experiencias vividas en los talleres nos permitieron comprender que existen diversos modos en el que las escrituras juveniles se hacen presentes a través de múltiples formas emergentes que se contraponen con las normas de escrituras y lecturas de la escuela y en muchas ocasiones de la sociedad en general. Por tanto, los cambios que la sociedad globalizada demanda en cuanto al uso de las tecnologías, escrituras y los mismos jóvenes que a través de sus acciones solicitan, se convierte en encuentros y desencuentros de comunicación juvenil. Sin embargo, existe la necesidad de atender su subjetividad y así aperturar la mirada hacia lo plural y diverso, dejando de lado el accionar adultocéntrico y hegemónico, con el propósito de reducir la brecha de la desigualdad social, educativa y cultural, ya que la exclusión y la segmentación desigual "son las dos principales consecuencias de la reestructuración" (García Canclini, 2004: 170).

En la multimodalidad textual observamos que los jóvenes estudiantes hacen usos diversificados de las tecnologías; apropiándose de ellos como espacios de recreación, expresión de sus sentires, deseos, emociones y experiencias de lo que viven cotidianamente. Así, la escuela como institución se ve rebasada, ya que la mayoría de los docentes que laboran en estos espacios desconocen las múltiples lecturas que los jóvenes hacen de sus recursos tecnológicos. Por lo que: "asumir posturas críticas y abiertas implica trabajar sobre el papel social de la educación y, en nuestro caso, sobre el papel social de los sujetos de la educación ante el cambio tecnológico" (De Alba, 2010: 86).

Finalmente consideramos que los y las jóvenes están ansiosos de ser escuchados, de interactuar, de develar sus experiencias de vida ligadas a su cultura, sociedad, en donde configuran saberes, subjetividades y formas particulares de escribir el mundo y de decir su palabra, sin embargo, el acceso y desigualdad se sigue acrecentando en gran parte de nuestro continente, y se hace visible en los rostros de los jóvenes, en sus interacciones y expresiones lingüísticas. 


\section{Referencias bibliográficas}

Area, Manuel, Begoña Gros y Miguel Marzal (2014), Alfabetizaciones y tecnologías de la información y la comunicación, Madrid, Editorial Síntesis.

Bárcena, Fernando y Joan-Carles Mèlich (2014), La educación como acontecimiento ético. Natalidad, narración y hospitalidad, Buenos Aires, Miño y Dávila.

Berlanga, Benjamín (2018), Educar con sujeto: experiencia, don y promesa (otro modo de relación con el otro que no sea el de intervención. Notas de una charla en el Seminario "Pedagogía de la indignación, pedagogía del sujeto", seminario coordinado por la UCIRED para el equipo del Centro de Derechos Humanos Victoria Diez, León.

Blumer, Herbert (1982), Interaccionismo simbólico: perspectiva y método, Bárcelona, Hora.

Castells, Manuel (2009), Comunicación y Poder, Madrid, Alianza Editorial.

Centro Latinoamericano y Caribeño de Demografía (2017), América Latina: estimaciones y proyecciones de población total, urbana y rural, y económicamente activa 1950-2050, disponible en https://www.cepal.org/es/temas/proyecciones-demograficas/estimaciones-proyecciones-poblacion-total-urbana-rural-economicamente-activa. [Sitio consultado el 6 de junio de 2020.]

Comisión Económica para América Latina y el Caribe (CEPAL) (2019), Panorama Social de América Latina, disponible en https://repositorio.cepal.org/bitstream/handle/11362/44969/5/ S1901133_es.pdf. [Sitio consultado el 29 de mayo de 2020.]

Chartier, Roger (2005), "Lenguas y lecturas en el mundo digital”, en El presente del pasado: escritura de la historia, historia de lo escrito, México, Universidad Iberoamericana, p. 195-220.

Chartier, Roger (2010), “Aprender a leer, leer para aprender”, en José Antonio Millán (ed.), La lectura en España: informe 2008, p. 23-42.

De Alba, Alicia (2010), "Internet: reto de inclusión social”, en José Carabajal Romero y Daniel Saur Moyano (eds.), El desafío tecnológico: transformaciones y fronteras educativas, México, Juan Pablos, Seminario de Análisis de Discurso Educativo, p. 79-92.

De Sousa, Boaventura, Santos (2010), Descolonizarel saber, reinventarel poder, Montevideo, Ediciones Trilce.

Espejel, Diana (2014), "La escritura del afecto: los vínculos entre los jóvenes en la cultura digital", en Sandra Flores (ed.), Redes sociales digitales: nuevas prácticas para la construcción cultural, México, Conaculta.

García Canclini, Néstor (2004), Diferentes, desiguales y desconectados: mapas de la interculturalidad, Barcelona, Gedisa.

Giddens, Anthony (1998), La constitución de la sociedad, Buenos Aires, Amorrortu. 
Haraway, Donna (1995), Ciencia, cyborgs y mujeres: la reinvención de la naturaleza, Madrid, Cátedra.

Instituto Mexicano de la Juventud (2006), Encuesta Nacional de la Juventud 2005, disponible en https://sic.cultura.gob.mx/ficha.php?table=centrodoc\&table_id=245 [Sitio consultado el 15 de octubre de 2020.]

Kalman, Judith (2004), Saber lo que es la letra: una experiencia de lectoescritura con mujeres de Mixquic, México, Siglo XXI.

Knobel, Michele. y Colin Lankshear (2013), "Remix: la nueva escritura popular", en Ana Sacristán (ed.), Sociedad del Conocimiento, Tecnología y Educación, Madrid, Morata.

Lankshear, Colin y Michele Knobel (2010), Nuevos alfabetismos: su práctica cotidiana y el aprendizaje en el aula, Madrid, Morata.

Mead, Margaret (2006), Cultura y compromiso: estudio sobre la ruptura generacional, Bercelona, Gedisa.

Mèlich, Joan-Carles (1998), Antropología simbólica y acción educativa, México, Paidós.

Mèlich, Joan-Carles (1998), Totalitarismo y fecundidad: la filosofía frente a Auschwitz, Barcelona, Anthropos.

Pérez Salazar, Gabriel (2014), "El meme en redes sociales: prácticas culturales de replicación en línea”, en Sandra G. Flores (ed,), Redes sociales digitales: nuevas prácticas para la construcción cultural, México, Consejo Nacional para la Cultura y las Artes, p. 113-132.

Reguillo, Rossana (2000), "La condición juvenil en el México contemporáneo: biografías, incertidumbres y lugares", en Rossana Reguillo (ed.), Los jóvenes en México, México, FCE-CNCA, p. 395-429.

Reguillo, Rossana (2005), Horizontes fragmentados: comunicación, cultura, pospolítica. El (des)orden global y sus figuras, Guadalajara, ITESO.

Saraví, Gonzalo (2015), Juventudes fragmentadas: socialización, clase y cultura en la construcción de la desigualdad, México, FLACSO-CIESAS.

Secretaria de Educación Pública (2014), Documento Base para el Servicio Educativo de Telebachillerato Comunitario, México, Secretaría de Educación Pública.

Sibilia, Paula (2012), "La escuela en un mundo hiperconectado: ¿redes en vez de muros?" Revista Educación y Pedagogía, vol. 24, n 62, disponible en https://revistas.udea.edu.co/index.php/revistaeyp/article/view/14199. [Sitio consultado 25 de mayo de 2020.]

Sunkel, Guillermo, Daniela Trucco y Andrés Espejo (2013), La integración de las tecnologías digitales en las escuelas de América Latina y el Caribe: una mirada multidimensional, Santiago de Chile, CEPAL, disponible en www.cepal.org/es/publicaciones/21681-la-integracion-tecnologias-digitales-escuelas-america-latina-caribe-mirada [Sitio consultado el 26 de octubre de 2020.] 
Vommaro, Pablo (2015), Juventudes y políticas en América Latina: tendencias, conflictos y desafíos, Ciudad Autónoma de Buenos Aires, Grupo Editor Universitario.

Weiss, Eduardo (2017), "El Telebachillerato Comunitario: una innovación curricular a discusión", Revista Latinoamericana de Estudios Educativos (México), vol. XLVII, n³ 3-4, p. 7-26.

Woods, Peter (1998), La etnografía en la investigación educativa, Barcelona, Ediciones Paidós.

Zimmermann, Klaus (1996). "Lenguaje juvenil, comunicación entre jóvenes y oralidad”. En Thomas Kotschi, Wulf Oesterreicher, Klaus Zimmermann (eds.), El español hablado y la cultura oral en España e Hispanoamérica, Madrid, Vervuert Iberoamérica. 